\title{
Happiness, Generativity and Social Preferences in a Developing Country: A Possibility of Future Design
}

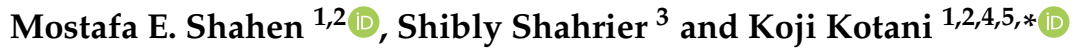 \\ 1 School of Economics and Management, Kochi University of Technology, 2-22, Eikokuji-cho, Kochi-shi, \\ Kochi 780-8515, Japan; mostafaelsayedshahen@gmail.com \\ 2 Research Institute for Future Design, Kochi University of Technology, A401 2-7-8 Otesuji, Kochi-shi, \\ Kochi 780-0842, Japan \\ 3 Department of Economics and Social Science, Brac University, 66 Mohakhali, Dhaka 1212, Bangladesh; \\ shibly.shahrier@bracu.ac.bd \\ 4 Urban Institute, Kyusyu University, Fukuoka 819-0395, Japan \\ 5 College of Business, Rikkyo University, Tokyo 171-8501, Japan \\ * Correspondence: kojikotani757@gmail.com
}

Received: 9 August 2019; Accepted: 20 September 2019; Published: 25 September 2019

\begin{abstract}
Happiness, generativity and social preferences are pivotal factors for the betterment and sustainability of societies. However, little is known about the relationships among happiness, generativity and social preferences, along with sociodemographic factors, within a single analytical framework. We hypothesize that generativity and social preferences are the determinants of happiness, posing a research question "Are people happier by being prosocial and/or generative for sustainability?" We conduct a survey experiment, collecting data from five subjective happiness scales, generativity, social value orientation and sociodemographic variables in one urban area (Dhaka) and two rural areas (Bogra and Gaibandha) in Bangladesh. With the data, we empirically characterize determinants of subjective happiness with a focus on generativity and social value orientation, controlling for sociodemographic factors. The statistical analysis consistently shows a positive association between subjective happiness and generativity, irrespective of the type of happiness scale, while social value orientation does not exhibit any significance. Rural residents have lower peer relative happiness than urban residents, and household income has a positive relationship with general subjective happiness, leading each of these factors to be significant in overall subjective happiness. In summary, generativity, income and residence area are main determinants of happiness, implying that further urbanization, which is expected to occur in the future, will positively affect people's happiness if it can bring about an increase in generativity. These results also suggest a possibility that people are happier by being more generative for sustainability, and some new institutional framework such as future design shall be recommended to enhance generativity.
\end{abstract}

Keywords: happiness; generativity; social value orientation; sociodemographic factors; developing countries; future design

\section{Introduction}

The greatest philosophers and scholars in history, such as Aristotle and Bentham, claim that happiness is an ultimate goal of human life [1,2]. In contemporary societies, happiness is interpreted as an outcome of a "good life," which is established to be driven by social status and/or some sociodemographic factors, and thus people are assumed to behave for pursuing happiness [3-6]. On the other hand, generativity and prosociality in human preferences and behaviors are claimed to be essential for the betterment and sustainability of societies $[7,8]$. This is because they are conceptualized 
as the concern and commitment for people in current and future generations, inducing a higher level of cooperation for various social and sustainability problems. Happiness and sustainability are fundamental foundations for human life; however, it is becoming a big challenge for contemporary societies to maintain sustainability, while people are pursuing happiness.

A majority of countries in the world adopt democracy and capitalism as a social institution, which provide individuals with freedom of choices for various products and services as well as freedom of speech to pursue further economic growth and prosperity [9-11]. However, it is reported that capitalism and democracy bring about consumerism and self-maximization behaviors to be the main sources of happiness, leading to emergence of various intragenerational and intergenerational problems for sustainability such as global climate change and accumulation of government debts in many countries [12-14]. In other words, capitalism and democracy are claimed to be institutions that cannot ensure sustainability along with happiness, and some researchers argue that existent social institutions or regimes, such as communism, may not be able to do so [10,15-18].

Sustainability can be ensured by solving not only intragenerational, but also intergenerational problems $[19,20]$. An intragenerational problem is a problem that arises among people in the same generation such as utilization of common pool resources and provision of public goods. Some literature demonstrates that prosocial people are likely to contribute more to the solution of such intragenerational problems [21]. On the other hand, an intergenerational problem is a problem that arises among people over different generations including future generations, such as climate change and government debt. Generativity (concern and commitment for future generations) or generative actions are claimed to be essential for the solutions of intergenerational problems through transferring skills, social capital as well as environmental and natural resources to future generations [22,23]. Thus, prosociality and generativity can be considered crucial factors for sustainability of societies.

A main concern is how to develop our societies in a sustainable way by solving intragenerational and intergenerational problems as well as how to improve or at least maintain happiness at the same time. To address these issues, we hypothesize that generativity and social preferences of prosociality are determinants of happiness, posing a research question "Are people happier by being prosocial and/or generative for sustainability?" We conduct a survey experiment, collecting data from five subjective happiness scales, generativity, social value orientation and sociodemographic variables in one urban area (Dhaka) and two rural areas (Bogra and Gaibandha) in Bangladesh. With the data, we empirically characterize determinants of subjective happiness with a focus on generativity and social value orientation, controlling for sociodemographic factors. Answering the research question enables us to suggest some institutions that ensure sustainability by inducing people to be prosocial and generative without compromising happiness. Some researchers advocate new institutions to connect people in the current generation with one another as well as with future generations to solve intragenerational and intergenerational problems, suggesting a new field of research, "future design" [24-26]. If our question is answered "yes," the future design can possibly be considered and recommended as a promising institution to be able to enhance generativity and prosociality for not only sustainability, but also happiness.

\section{Literature Review}

Social status and/or sociodemographic factors have been studied as the possible determinants of a "good life," leading to an increase in individual happiness. The previous literature has focused on examining the association of particular economic factors and urbanization with happiness. Income is generally reported to have a positive relationship with happiness, while age, gender, education and religion show mixed outcomes [27-30]. Requena and Kim [31,32] compare people's happiness between rural and urban areas in both developed and developing countries. They illustrate that rural residents have less happiness than urban residents in developing countries, while the opposite is true in developed countries. They argue that the result may be due to living standards and the availability of public goods, depending on the stages of economic development. 
Several studies in psychology have examined the correlation between generativity and happiness. The authors in $[7,33,34]$ collect data using a generativity behavioral checklist (GBC) from student and adult subject pools in the USA, establishing a positive correlation. Steward et al. [35] study a temporal change in happiness in middle-aged women in the USA, finding that happiness does not necessarily decline in age and has a positive association with generativity. The authors in [36-40] address the possible mediators between happiness, life satisfaction and generativity for student and adult subjects. They find that some mediators, such as symbolic immortality and altruism, explain the relationships among the factors. Other studies have focused on the relationship between sustainability and generativity. Jia et al. [41,42] study how generativity is related to sustainable attitudes towards the environment (i.e., environmentalism) and find that people with high generativity tend to be more sustainable for environment. Matsuba et al. [43] also find that the engagement in generative activities leads people to take sustainable and environmental actions.

The research on happiness and sustainability along with social behaviors and preferences has attracted much interest in the last few decades. The literature finds that a prosocial behavior (i.e., charity or buying some gifts for friends) has a positive association with happiness, demonstrating that prosocial acts and individual happiness have a positive feedback loop [44-48]. Some research has focused on the relationship between social preferences and sustainability. Kamijo et al. and Shahrier et al. $[49,50]$ have studied intergenerational sustainability and find that prosociality play an important role in taking sustainable actions. Timilsina et al. [21] show that prosociality is an influential factor to characterize sustainable harvesting behaviors for common pool resources.

Previous studies have established that there is a positive association between happiness and generativity using two-variable correlation analysis and prosocial acts tend to increase happiness. However, it is claimed that prosocial acts are at most spontaneous or temporal, and it is important to consider individual social preferences along with sociodemographic factors because the preference is established to be stable or not to change in the long run [46,51,52]. Moreover, little is known about the relationships among happiness, generativity and social preferences, along with sociodemographic factors, within a single analytical framework, despite the importance of the three factors in understanding the betterment and sustainability of societies in the future.

Based on the past studies, our survey experiment employs subjective happiness scale (SHS), generative behavior checklist (GBC) and social value orientation (SVO) for subjects' happiness, generativity and social preferences of prosociality, respectively [7,53-56]. We use the SHS as it is known to be a reliable and widely used scale for measuring individual happiness $[55,57,58]$. The GBC is the best measurement in the field research because of its simplicity; subjects simply need to answer whether they have taken specific generative activities and the frequencies in the list for the last two months [7,54]. A triple dominance method is chosen for SVO because it is demonstrated that Bangladeshi subjects can easily understand and it is effective for the purpose of comparison [53,56,59].

\section{Methods and Materials}

We conducted a questionnaire survey and experiment in three districts of Bangladesh: Dhaka, Bogra and Gaibandha (Figure 1). We consider them to be one urban area, Dhaka, and two rural areas, Bogra and Gaibandha. We choose the regions because they possess the same culture, language and religious variation, except sociodemographic factors and economic development, where Bangladesh is culturally and ethnically a homogeneous country. Dhaka is the capital city, representing an urban society, and is located between $23^{\circ} 55^{\prime}$ and $24^{\circ} 81^{\prime}$ north latitude and between $90^{\circ} 18^{\prime}$ and $90^{\circ} 57^{\prime}$ east longitude [60]. The population, population density and total area are 14.51 million, $10,484 \mathrm{~km}^{-2}$ and $1371 \mathrm{~km}^{2}$, respectively, which makes Dhaka the most populated city in the world. 


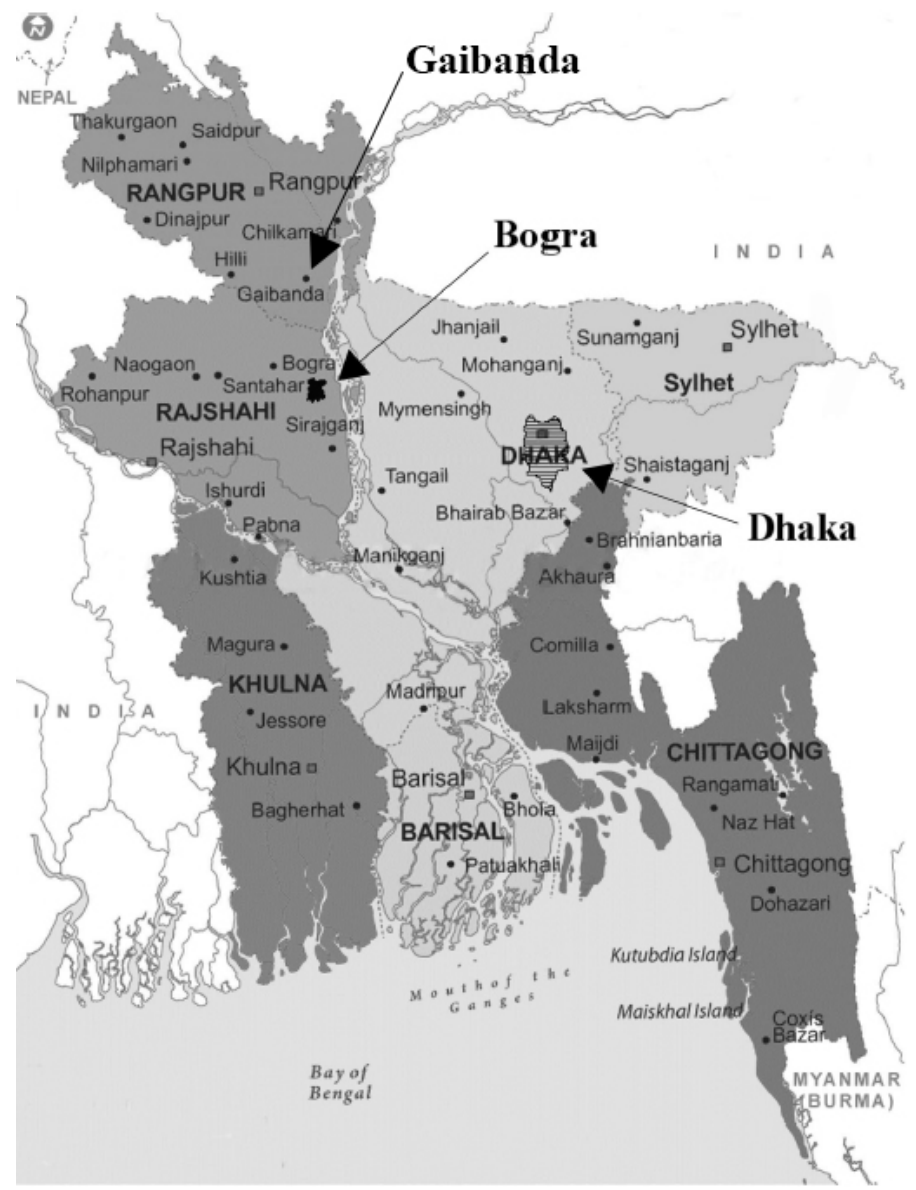

Figure 1. Map of Bangladesh.

The rural areas consist of two districts: (i) Bogra and (ii) Gaibandha. Bogra consists of two unions of the Shajahanpur subdistrict in the northern districts, Amrool and Chopinagar (Figure 1). The location of the Shajhanpur subdistrict is between $24^{\circ} 41^{\prime}$ and $24^{\circ} 50^{\prime}$ north latitude and between $89^{\circ} 16^{\prime}$ and $89^{\circ} 29^{\prime}$ east longitude. Shajhanpur's land area is 54,783 acres; Amrool and Chopinagar's land area is 6106 acres and 4048 acres, respectively [61]. The population densities in Amrool and Chopinagar are $951 \mathrm{~km}^{-2}$ and $1357 \mathrm{~km}^{-2}$, respectively, whereas the country average is $1218 \mathrm{~km}^{-2}$ [61]. The villages in these two unions are agrarian societies, while agro-based and small-scale businesses are found in very limited areas.

Gaibandha comprises three unions of the Palashbari subdistrict: Harinathpur, Hossainpur and Monoharpur. The location of Palashbari is between $25^{\circ} 11^{\prime}$ and $25^{\circ} 19^{\prime}$ north latitude and between $89^{\circ} 16^{\prime}$ and $89^{\circ} 32^{\prime}$ east longitude. The land area, population density and total population in the Palashbari are 45,774 acres, $1321 \mathrm{~km}^{-2}$ and 244,792, respectively [61]. The villages in the unions are also agrarian societies, and they are considered the least developed in Bangladesh. All the dwellers engage in farming either as subsistence farmers or as cash-crop farmers. In what follows, we refer to these study areas as Bogra and Gaibandha, interchangeably mentioning them as rural areas.

We collected 105 subjects in Dhaka using an individual survey based on our randomization on the proportion of each occupation in the population [62]. The number of subjects needed in each occupation was determined, and we selected a certain number of organizations for each occupation. Then, we contacted these organizations, and we randomly invited subjects from these organizations based on their responses. The response rates for organizations and for subjects were $50 \%$ and $60 \%$, respectively. We collected 142 and 150 subjects in two rural areas of Bogra and Gaibandha, respectively, using an individual survey with the following random sampling procedures. First, we obtained a list of the households that reside in Bogra and Gaibandha from local city offices, and we randomly 
chose households that approximate the representatives for each area. Second, we sent a letter to invite one member (who earns an income) from each household to participate in our survey and experiment, and the response rate was $75 \%$. As of the measurement for the main variables in our analysis, the subjective happiness scale (SHS), generative behavioral checklist (GBC) and social value orientation (SVO) were employed to represent subjects' happiness, generativity and social preferences, respectively [7,53-56] (see the Supplementary Materials of our questionnaire).

We use the subjective happiness scale with a four-item measurement developed by Lyubomirsky and Lepper [55], where each item is rated on a 7-point Likert scale. The first question in the scale reports individual absolute self-rated happiness (AH) by stating, "In general, I consider myself," and its anchors are "not a very happy person" and "a very happy person." The second item reports individual relative happiness as compared to that of peers by stating, "Compared to my peers, I consider myself," and its anchors are "less happy" or "more happy"; it is called peer relative happiness (PRH). The third and fourth items correspond to a general description of a happy and/or unhappy person, where subjects make a choice to describe themselves best. In the items-"Some people are generally very happy. They enjoy life no matter what is going on, getting the most of everything. How much does this sentence describe you?" and "Some people are generally not very happy. Although they are not depressed, they never seem as happy as they might be. How much does this sentence describe you?" - the anchors are "not at all" and "a great deal," which are called general subjective happiness and unhappiness (i.e., GSH and GSU), respectively. To calculate the overall subjective happiness $(\mathrm{OSH})$, the average of the four items is calculated, while the fourth item is reversely coded.

The generative behavior checklist (GBC) developed by de St Aubin and McAdams [7] is employed to measure the frequency of people's generative behaviors in the last two months. This measure contains a list of 50 activities, of which only 40 activities are considered indicators of "generativity." "Taught somebody a skill," "Gave money to a charity," "Made a decision that influenced many people" and "Served as a role model for a young person" are some examples of the generative activities. Subjects need to choose one of the three options for each activity. The "zero," "one" or "two" scores indicate that subjects have not participated in each generative activity, participated in it once or participated in it more than once over the last two months, respectively. The generativity score for each subject is calculated as the sum of the scores for all 40 items.

Social value orientation (SVO) developed by Van Lange et al. [53] is employed to identify the social preference of each subject. This game consists of nine items, each of which contains three choices. Subjects are asked to make one choice for each item, dividing an amount of money between himself/herself and a stranger; for example, (A) you get 500, and the other gets 100; (B) you get 500 , and the other gets 500; and (C) you get 560, and the other gets 330. Option (A) represents the competitive person, as it maximizes the gap between self point and the other's point $(500-100=400)$. Option (B) represents the prosocial person, as it maximizes the joint benefit $(500+500=1000)$, while option (C) is the individualistic person, as it maximizes its own benefits without considering those of others [56]. Four types of individual SVOs are identified by this game, i.e., individualistic, competitive, prosocial and unidentified, based on their choices in the game. When the subject makes a consistent choice in six items for one orientation (i.e., individualistic, competitive or prosocial), then he/she is considered to be that orientation, and otherwise, he/she is considered to be "unidentified." We drop all the "unidentified" subjects from our data because we can not specify their social preference. We randomly match two subjects as a pair to compute their final payoff based on their performances in the game. Subjects are paid on average $100 \mathrm{BDT}$ for the SVO, while a fixed participation fee of $150 \mathrm{BDT}$ is paid to all subjects, and the total payment on average is $250 \mathrm{BDT}$ per subject.

Our main goal of this paper is to study the effect of sustainability determinants (i.e., generativity and social preferences) on happiness while controlling for other factors. To this end, parametric and nonparametric statistical analyses are employed by utilizing the data of SHS, GBC, SVO and sociodemographic factors collected in a questionnaire survey and experiment. Nonparametric Mann-Whitney test is applied to check the difference in the distributions of subjective happiness (SH) 
between the urban and rural areas or between the prosocial and proself orientations in SVO, while Pearson's correlation is applied to discover the nature of the relationship between SH and generativity and the key sociodemographic factors. To examine the effect of generativity and social preferences on happiness holding other factors fixed, we also employ regression analyses to quantitatively identify the determinants of SHS. Poisson regression is applied for the four components of SHS, as the scales are count variables (i.e., absolute self-rated happiness (AH), peer relative happiness (PRH), general subjective happiness (GSH) and general subjective unhappiness (GSU)), while we apply ordinary least squares (OLS) for the aggregate SHS (i.e., overall subjective happiness), as it is a continuous variable. The following equation is estimated for Poisson regression and OLS $(k \in\{\mathrm{AH}, \mathrm{PRH}, \mathrm{GSH}, \mathrm{GSU}, \mathrm{OSH}\})$ :

$$
Y^{k}=\beta_{0}^{k}+\beta_{1}^{k} X+\beta_{2}^{k} S+\beta_{3}^{k} Z+\epsilon^{k},
$$

where $Y^{k}$ is the explained variable (AH, PRH, GSH, GSU and OSH), $X$ is the generativity score of subjects, $S$ is a dummy variable representing $S V O$ that takes unity for individualistic and competitive subjects (i.e., proself) and 0 , otherwise, $\mathrm{Z}$ is a vector of sociodemographic variables that may affect $\mathrm{SH}$, and $\epsilon^{k}$ is the error term (see Table 1 for the definitions of every variable used in the statistical analysis). The parameters $\beta_{i}$ s for $i=0,1,2$ are the coefficients of the intercept, $X$ and $S$, and $\beta_{3}$ is a vector of the coefficients for independent variables $Z$ related to the sociodemographic factors.

With the regression analysis of Equation (1), we intend to examine a conceptual framework for the relationships among subjective happiness $(\mathrm{SH})$, generativity and $\mathrm{SVO}$, along with sociodemographic factors in Figure 2. In this framework, a coefficient of each key variable, $\beta_{i}, i=0,1,2$, is considered to represent the marginal effect of that variable on $\mathrm{SH}$ after the effects of the other variables are netted out $[63,64]$. For example, $\beta_{1}$ is considered to represent the effect of generativity on $\mathrm{SH}$ after the effects of SVO and the sociodemographic factors have been netted out, while some possible mediators may play roles in characterizing subjective happiness through several independent variables. In this research, our focus is on estimating $\beta_{1}, \beta_{2}$ and $\beta_{3}$ in Figure 2. The interpretation of these coefficients in Poisson regression is derived as follows [63]: the marginal effect of a continuous independent variable such as generativity should be calculated using the formula of $100 \times \beta_{j}$ to be a percentage change in $Y$ when the continuous variable increases by one unit. In the case of a dummy independent variable such as $\mathrm{SVO}$ (proself $=1$, and otherwise, 0 ), it is calculated by $\exp \left(\beta_{j}\right)-1$ being interpreted as a percentage change in $Y$ when the dummy variable increases from 0 to 1 .

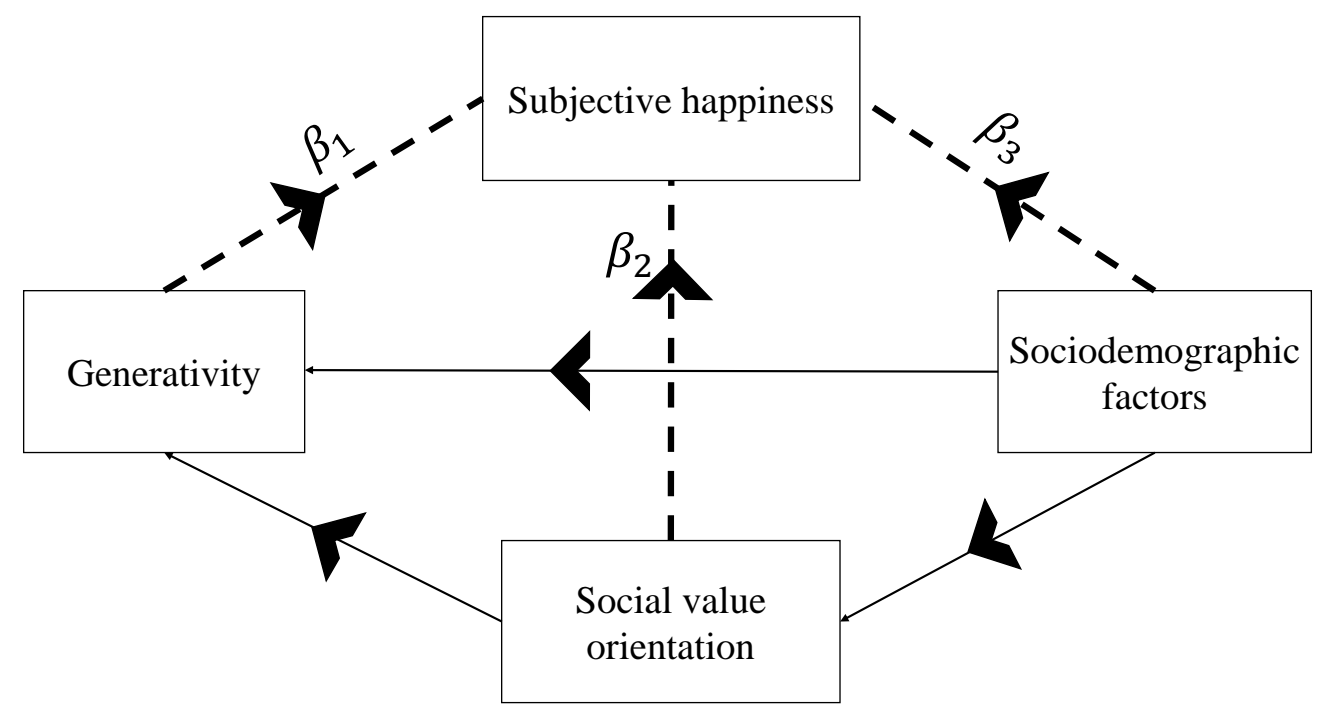

Figure 2. A conceptual framework for the relationships among subjective happiness, generativity, social value orientation and sociodemographic factors. 
Table 1. Summary statistics.

\begin{tabular}{|c|c|c|c|c|c|c|c|c|c|c|c|c|c|c|c|}
\hline & \multicolumn{5}{|c|}{$\begin{array}{l}\text { Urban } \\
\text { (Dhaka) }\end{array}$} & \multicolumn{5}{|c|}{$\begin{array}{l}\text { Rural } \\
\text { (Bogra and Gaibandha) }\end{array}$} & \multicolumn{5}{|c|}{ Overall } \\
\hline & Mean & Median & SD & Min & Max & Mean & Median & SD & Min & $\operatorname{Max}$ & Mean & Median & SD & Min & $\operatorname{Max}$ \\
\hline Generativity ${ }^{1}$ & 28.57 & 28 & 12.30 & 6 & 66 & 29.25 & 29 & 11.88 & 2 & 70 & 29.07 & 29 & 11.98 & 2 & 70 \\
\hline \multicolumn{16}{|l|}{ SVO } \\
\hline Proself 2 & 0.84 & - & 0.37 & 0 & 1 & 0.64 & - & 0.48 & 0 & 1 & 0.70 & - & 0.46 & 0 & 1 \\
\hline Competitive & 0.22 & 0 & 0.42 & 0 & 1 & 0.29 & 0 & 0.45 & 0 & 1 & 0.27 & 0 & 0.44 & 0 & 1 \\
\hline Individualistic & 0.62 & 1 & 0.49 & 0 & 1 & 0.36 & 0 & 0.48 & 0 & 1 & 0.42 & 0 & 0.49 & 0 & 1 \\
\hline Prosocial & 0.16 & 0 & 0.37 & 0 & 1 & 0.36 & 0 & 0.48 & 0 & 1 & 0.30 & 0 & 0.46 & 0 & 1 \\
\hline \multicolumn{16}{|l|}{ Age } \\
\hline$(<20)$ & 0.68 & 1 & 0.47 & 0 & 1 & 0.49 & 0 & 0.50 & 0 & 1 & 0.54 & 1 & 0.5 & 0 & 1 \\
\hline$(20-29)$ & 0.25 & 0 & 0.43 & 0 & 1 & 0.26 & 0 & 0.44 & 0 & 1 & 0.25 & 0 & 0.44 & 0 & 1 \\
\hline$(30-39)$ & 0.04 & 0 & 0.18 & 0 & 1 & 0.11 & 0 & 0.31 & 0 & 1 & 0.09 & 0 & 0.29 & 0 & 1 \\
\hline$(40-49)$ & 0.04 & 0 & 0.18 & 0 & 1 & 0.08 & 0 & 0.27 & 0 & 1 & 0.07 & 0 & 0.25 & 0 & 1 \\
\hline$(50-59)$ & 0 & 0 & 0 & 0 & 0 & 0.05 & 0 & 0.23 & 0 & 1 & 0.04 & 0 & 0.19 & 0 & 1 \\
\hline$(>60)$ & 0 & 0 & 0 & 0 & 0 & 0.01 & 0 & 0.11 & 0 & 1 & 0.008 & 0 & 0.09 & 0 & 1 \\
\hline Years of education & 12.68 & 16 & 4.91 & 0 & 20 & 8.97 & 10 & 3.86 & 0 & 17 & 9.95 & 10 & 4.47 & 0 & 20 \\
\hline Household income in thousands & 47.73 & 30 & 49.02 & 7 & 300 & 16.56 & 12 & 21.41 & 0.50 & 250 & 24.81 & 15 & 34.02 & 0.50 & 300 \\
\hline Gender $^{3}$ & 0.16 & - & 0.37 & 0 & 1 & 0.04 & - & 0.21 & 0 & 1 & 0.07 & - & 0.26 & 0 & 1 \\
\hline Religion 4 & 0.07 & - & 0.26 & 0 & 1 & 0.01 & - & 0.09 & 0 & 1 & 0.02 & - & 0.15 & 0 & 1 \\
\hline No. of siblings 5 & 4.05 & 4 & 2.14 & 1 & 11 & 4.54 & 4 & 2.34 & 1 & 14 & 4.41 & 4 & 2.30 & 1 & 14 \\
\hline Family structure 6 & 0.30 & 0 & 0.46 & 0 & 1 & 0.38 & 0 & 0.49 & 0 & 1 & 0.36 & 0 & 0.48 & 0 & 1 \\
\hline Rural (Bogra and Gaibandha) ${ }^{7}$ & - & - & - & - & - & - & - & - & - & - & 0.74 & 1 & 0.44 & 0 & 1 \\
\hline \multicolumn{16}{|l|}{ Subjective happiness scales (SHS) } \\
\hline Absolute self-rated happiness $(\mathrm{AH})$ & 4.91 & 5 & 1.36 & 1 & 7 & 4.79 & 5 & 1.44 & 1 & 7 & 4.82 & 5 & 1.42 & 1 & 7 \\
\hline Peer relative happiness (PRH) & 5.08 & 5 & 1.42 & 1 & 7 & 4.66 & 5 & 1.51 & 1 & 7 & 4.77 & 5 & 1.50 & 1 & 7 \\
\hline General subjective happiness (GSH) & 5.22 & 5 & 1.47 & 1 & 7 & 4.82 & 5 & 1.38 & 1 & 7 & 4.93 & 5 & 1.42 & 1 & 7 \\
\hline General subjective unhappiness (GSU) & 2.72 & 2 & 1.68 & 1 & 7 & 3.38 & 3 & 1.66 & 1 & 7 & 3.21 & 3 & 1.69 & 1 & 7 \\
\hline Overall subjective happiness (OSH) & 5.12 & 5.25 & 0.99 & 2.50 & 7 & 4.72 & 4.75 & 1.05 & 1.50 & 7 & 4.83 & 4.75 & 1.05 & 1.50 & 7 \\
\hline Observations & 105 & & & & & 292 & & & & & 337 & & & & \\
\hline
\end{tabular}

${ }^{1}$ Generativity is defined as a count variable that takes values from 0 to 70 based on how many activities subjects have done in the last two months from a generativity behavior checklist. ${ }^{2}$ Proself is a dummy variable for $\mathrm{SVO}$, and it takes the value of 1 if the subject is characterized as individualistic or competitive and 0 , otherwise. ${ }^{3}$ Gender is a dummy variable that takes a value of 1 when the subject is male and 0 , otherwise. ${ }^{4}$ Religion is a dummy variable that takes a value of 1 when the subject is non-Muslim and 0 , otherwise. ${ }^{5}$ No. of siblings is a count variable for the number of siblings. ${ }^{6}$ Family structure is a dummy variable that takes a value of 1 when it is a joint family and 0 , otherwise. ${ }^{7}$ Rural is a dummy variable that takes a value of 1 when a subject is living in Bogra and Gaibandha and 0 otherwise. 
Results

Table 1 presents basic statistics of generativity, social value orientation (SVO), sociodemographic variables and subjective happiness (SH) for urban subjects (Dhaka), rural subjects (Bogra and Gaibandha) and all subjects in the sample. The mean score of subjects' generativity in the urban area, rural areas and overall sample are fairly similar at 28.57 points $(\mathrm{SD}=12.3), 29.25$ points $(\mathrm{SD}=11.88)$ and 29.09 points $(\mathrm{SD}=11.98)$, respectively. In contrast, $\mathrm{SVO}$ is different among the urban area, rural areas and overall sample, as the percentages of proself subjects are $84 \%, 64 \%$ and $70 \%$, respectively. The result is consistent with the previous literature in the sense that the percentage of proself people becomes higher in urban areas than in rural areas $[8,21,59]$. Another difference is in the average year of education, as urban subjects have 12.68 years $(\mathrm{SD}=4.91)$, rural subjects have 8.97 years $(\mathrm{SD}=3.86)$ and overall subjects in the sample have 9.95 years $(\mathrm{SD}=4.47)$ on average.

The largest variation in the sample is found in average household income, as it is 47.7 thousand BDT (SD = 49.02), 16.6 thousand BDT $(\mathrm{SD}=21.41)$ and 24.81 thousand BDT $(\mathrm{SD}=34.02)$ in the urban area, rural areas and overall sample, respectively. Regarding happiness, urban subjects have a higher $\mathrm{SH}$ in the four scales of the subjective happiness scale than rural subjects and overall subjects in the sample, leading the overall subjective happiness (OSH) to be higher for urban subjects with an average of 5.12 points $(\mathrm{SD}=0.99)$ than rural subjects with an average of 4.72 points $(\mathrm{SD}=1.05)$ and overall subjects in the sample with an average of 4.83 points $(\mathrm{SD}=1.69)$. These statistics suggest that urban subjects may generally have a higher level of $\mathrm{SH}$ than rural subjects, regardless of happiness scales, which is in line with Requena and Kim [31,32].

Figure 3 is a histogram to present the distribution of OSH for overall subjects in the sample, where the vertical axis denotes the frequencies, and the horizontal axis denotes OSH. The highest spike is found between 4.5 and 5 points, and the distribution appears to follow a normal distribution but is slightly skewed on one side (almost a bell-shaped distribution). We run a Shapiro-Francia normality test with the null hypothesis that the OSH distribution is normal. The result shows that the null hypothesis is not rejected, even with a $10 \%$ significance level, meaning that the OSH distribution follows a normal distribution. Therefore, we run an ordinary least squares (OLS) regression for $\mathrm{OSH}$, while other happiness scales are analyzed by applying Poisson regressions. Figure 4 presents a scatterplot between OSH (vertical axis) and generativity (horizontal axis), where one dot represents an observation for each subject in our sample. This scatterplot appears to suggest that there is a positive association between the two, and we confirm that there is a positive association between OSH and generativity using Pearson correlation $(r=0.11, p<0.03)$.

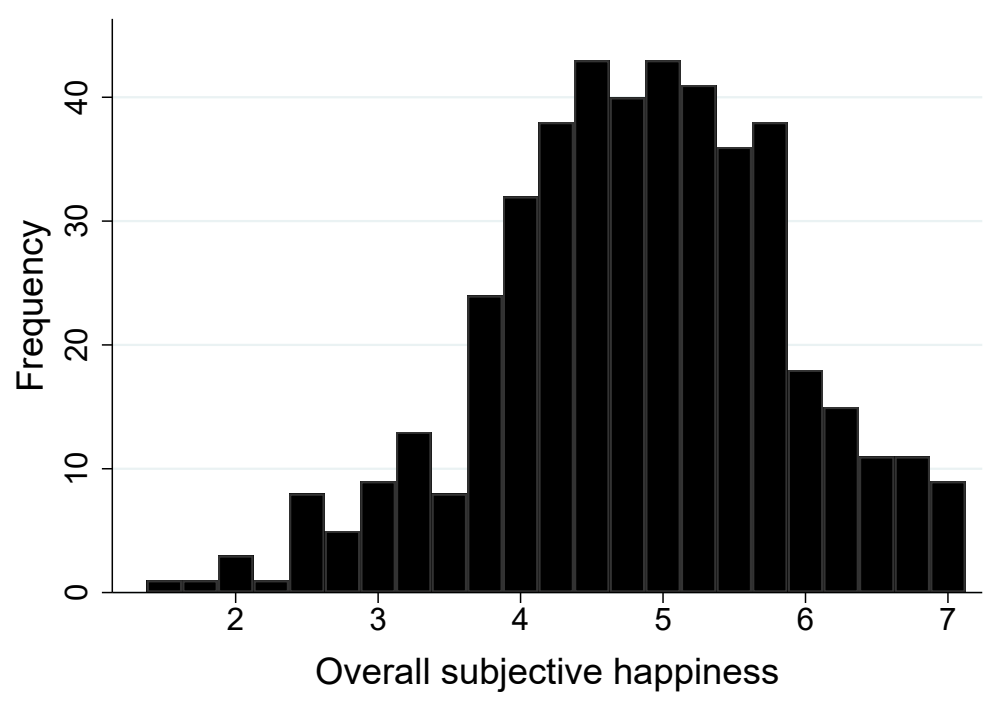

Figure 3. Frequency distribution of overall subjective happiness (OSH). 


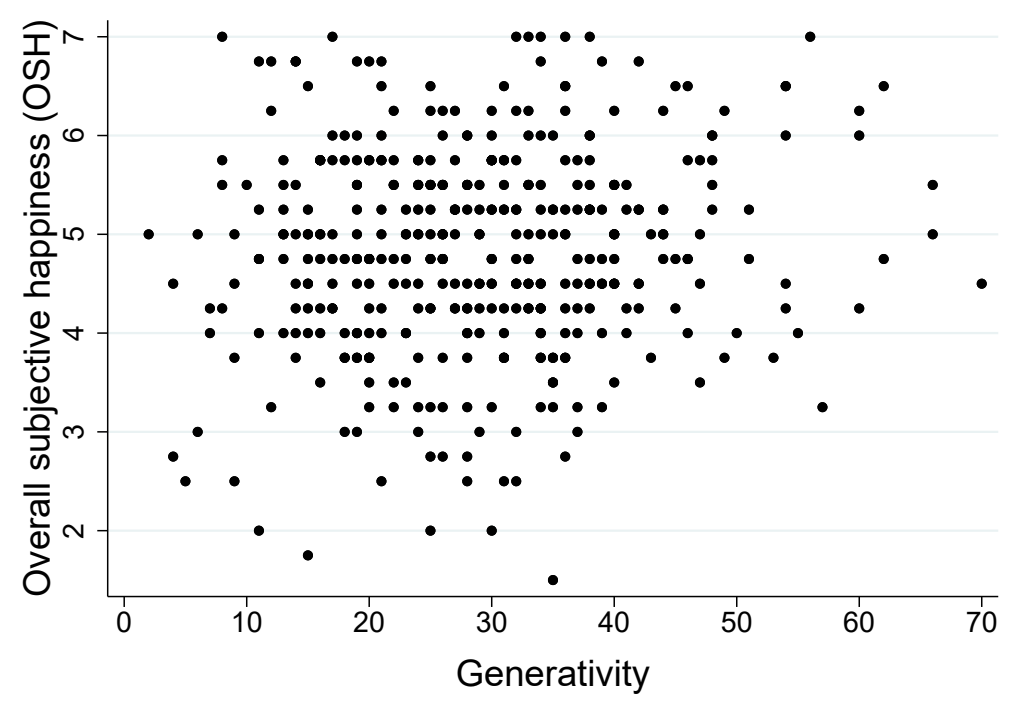

Figure 4. A scatterplot between overall subjective happiness $(\mathrm{OSH})$ and generativity.

Figure 5 is a boxplot to demonstrate a difference in OSH distributions between prosocial and proself subjects. The OSH distribution in proself subjects is slightly higher than that in prosocial subjects with respect to the medians and supports. To statistically check the distributional difference, we run a Mann-Whitney test with the null hypothesis that the OSH distributions between proself and prosocial subjects are the same. The result shows that there is no significant difference in the OSH distributions between prosocial and proself subjects $(Z=-0.426, p=0.67)$. We next examine the relationship between $\mathrm{OSH}$ and key sociodemographic factors, such as household income and residence areas. The Pearson correlation coefficients demonstrate that $\mathrm{OSH}$ and household income (residence area) have a positive (negative) association with $r=0.18, p<0.01(r=-0.15, p<0.01)$. Figure 6 is a boxplot to visualize a difference in the OSH distributions between rural and urban subjects, showing that urban subjects tend to have higher OSH than rural subjects. The Mann-Whitney test confirms that there is a significant difference in OSH distributions $(Z=3.38, p<0.01)$ between urban and rural subjects. Overall, these statistical analyses suggest that generativity, income and residence area could be considered possible determinants of subjective happiness, while SVO may not.

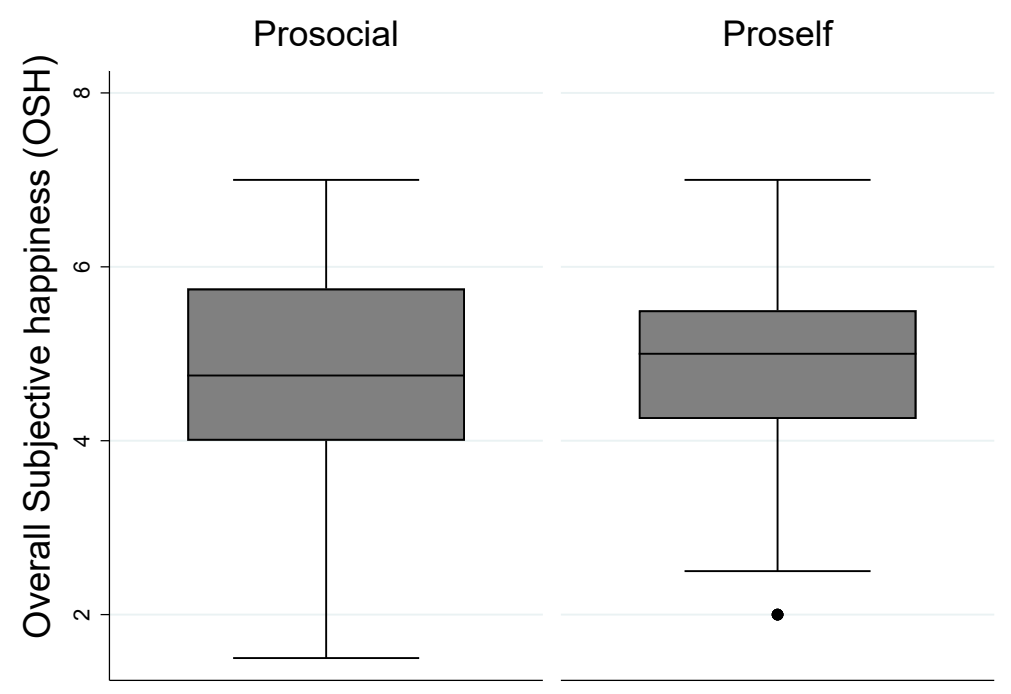

Figure 5. A boxplot between overall subjective happiness (OSH) and social value orientation (SVO). 


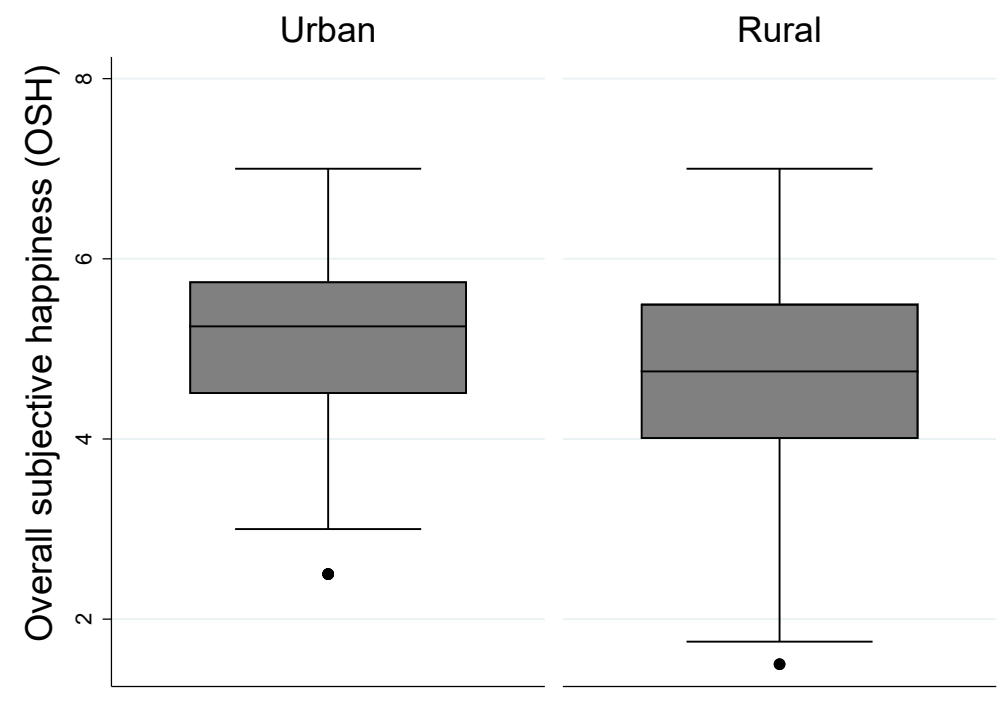

Figure 6. A boxplot between overall subjective happiness $(\mathrm{OSH})$ and residence areas.

We conduct regression analyses to quantitatively understand how $\mathrm{SH}$ is characterized by generativity, SVO, household income and residence area, controlling for other sociodemographic factors (see Table 2). We have tried different specifications for the regression models to check the robustness of our results, confirming that the main results in Table 2 remain the same. The first four columns in Table 2 present the marginal effects of the independent variables on the four components of the subjective happiness scale, such as absolute self-rated happiness $(\mathrm{AH})$, peer relative happiness (PRH), general subjective happiness (GSH) and general subjective unhappiness (GSU), using Poisson regressions, and the last column shows the marginal effect on overall subjective happiness (OSH) using OLS. The results reveal that generativity is statistically significant (i.e., $p<0.05$ except in $\mathrm{AH}$ regression $p<0.10$ and $p<0.01$ in GSH regression) across the four different scales of SH and OSH. More specifically, the expected AH, PRH and GSH increase by $13.4 \%, 15.8 \%$ and $31.1 \%$, respectively, and GSU declines by $18.8 \%$, with a rise in subjects' generativity score by one standard deviation (SD). The relationship between OSH and subjects' generativity score is consistent with the four scales of $\mathrm{SH}$, as $\mathrm{OSH}$ increases by 0.106 points when subjects' generativity score increases by one SD. These results show that generativity is a consistent and robust determinant across all scales of SH and OSH, indicating that subjects' generativity could be one of the most important factors of their happiness.

Table 2 shows that residence area and household income are the only sociodemographic factors that show statistical significance and are associated with different subjective happiness scales. The PRH and OSH for rural subjects are $41 \%$ and 0.25 points lower, respectively, than these for urban subjects (As mentioned in Section 3, the marginal effect of a dummy variable on PRH (OSH) is calculated by the following formula: $\exp \left(\beta_{j}\right)-1$, where $\beta_{j}$ is an estimated coefficient for the dummy variable. For instance, $\exp (0.347)-1 \approx 0.41=41 \%)$. An increase in household income by $10 \mathrm{BDT}$ is associated with a rise in GSH and $\mathrm{OSH}$ by $5 \%$ and 0.04 points, respectively. We also calculate the marginal rate of substitution (MRS) between household income and generativity by taking the natural logarithm for overall subjective happiness, generativity and household income and rerunning OLS regression. We obtain MRS $=\frac{\text { Percent change in generativity }}{\text { Percent change in income }}=-1.14$, meaning that, to maintain the same level of happiness, one percent of household income must be substituted by 1.14 percent of generativity or vice versa. This indicates that the effect of generativity is economically significant because it has almost the same magnitude as the effect of household income. The results demonstrate that generativity, urban/rural difference and household income are main determinants of $\mathrm{SH}$, which can be considered to be in line with the previous literature. de St Aubin and McAdams [33] find that generativity is positively correlated with $\mathrm{SH}$, and Ball and Chernova [65] demonstrate that there is a strong positive 
relationship between income and SH. In developing countries, Requena [31] confirms that subjects in urban areas have a higher level of SH than subjects in rural areas.

Table 2. Regression results.

\begin{tabular}{|c|c|c|c|c|c|}
\hline \multirow[b]{2}{*}{ Variables } & \multicolumn{4}{|c|}{ Poisson Regression } & \multirow{2}{*}{\begin{tabular}{l}
\multicolumn{1}{c}{ OLS } \\
\multicolumn{1}{c}{$(5)$} \\
Overall \\
Subjective \\
Happiness \\
(OSH)
\end{tabular}} \\
\hline & $\begin{array}{l}\quad(1) \\
\text { Absolute } \\
\text { Self-Rated } \\
\text { Happiness } \\
\text { (AH) }\end{array}$ & $\begin{array}{l}\quad(2) \\
\text { Peer } \\
\text { Relative } \\
\text { Happiness } \\
\text { (PRH) }\end{array}$ & $\begin{array}{l}\quad(3) \\
\text { General } \\
\text { Subjective } \\
\text { Happiness } \\
\text { (GSH) }\end{array}$ & $\begin{array}{l}\quad \text { (4) } \\
\text { General } \\
\text { Subjective } \\
\text { Unhappiness } \\
\text { (GSU) }\end{array}$ & \\
\hline Standardized values of generativity & $\begin{array}{l}0.134 * \\
(0.069)\end{array}$ & $\begin{array}{c}0.158 * * \\
(0.073)\end{array}$ & $\begin{array}{c}0.311^{* * *} \\
(0.077)\end{array}$ & $\begin{array}{c}-0.188^{* *} \\
(0.094)\end{array}$ & $\begin{array}{c}0.106^{* *} \\
(0.053)\end{array}$ \\
\hline Proself & $\begin{array}{c}0.233 \\
(0.167)\end{array}$ & $\begin{array}{c}-0.008 \\
(0.168)\end{array}$ & $\begin{array}{c}-0.086 \\
(0.160)\end{array}$ & $\begin{array}{c}0.109 \\
(0.201)\end{array}$ & $\begin{array}{c}0.062 \\
(0.124)\end{array}$ \\
\hline Rural (Bogra and Gaibandha) & $\begin{array}{l}-0.054 \\
(0.197)\end{array}$ & $\begin{array}{c}-0.347 \text { * } \\
(0.188)\end{array}$ & $\begin{array}{l}-0.251 \\
(0.181)\end{array}$ & $\begin{array}{l}-0.367 \\
(0.224)\end{array}$ & $\begin{array}{c}-0.257^{*} \\
(0.132)\end{array}$ \\
\hline Age & $\begin{array}{c}0.146 \\
(0.171)\end{array}$ & $\begin{array}{l}0.0013 \\
(0.179)\end{array}$ & $\begin{array}{l}0.0863 \\
(0.172)\end{array}$ & $\begin{array}{l}0.0932 \\
(0.208)\end{array}$ & $\begin{array}{l}0.0801 \\
(0.126)\end{array}$ \\
\hline Age square & $\begin{array}{l}-0.019 \\
(0.046)\end{array}$ & $\begin{array}{c}0.036 \\
(0.043)\end{array}$ & $\begin{array}{l}-0.013 \\
(0.044)\end{array}$ & $\begin{array}{l}-0.009 \\
(0.052)\end{array}$ & $\begin{array}{c}-0.0006 \\
(0.030)\end{array}$ \\
\hline Years of education & $\begin{array}{c}-0.0122 \\
(0.018)\end{array}$ & $\begin{array}{l}0.0135 \\
(0.020)\end{array}$ & $\begin{array}{c}-0.0007 \\
(0.019)\end{array}$ & $\begin{array}{l}0.0207 \\
(0.021)\end{array}$ & $\begin{array}{c}0.005 \\
(0.014)\end{array}$ \\
\hline Household income in thousand & $\begin{array}{c}0.003 \\
(0.004)\end{array}$ & $\begin{array}{c}0.002 \\
(0.002)\end{array}$ & $\begin{array}{c}0.005^{* * *} \\
(0.002)\end{array}$ & $\begin{array}{c}0.004 \\
(0.002)\end{array}$ & $\begin{array}{l}0.004^{* *} \\
(0.002)\end{array}$ \\
\hline Female & $\begin{array}{c}0.436 \\
(0.300)\end{array}$ & $\begin{array}{c}0.152 \\
(0.359)\end{array}$ & $\begin{array}{c}0.223 \\
(0.343)\end{array}$ & $\begin{array}{c}0.07 \\
(0.348)\end{array}$ & $\begin{array}{c}0.229 \\
(0.231)\end{array}$ \\
\hline Religion & $\begin{array}{c}-0.0157 \\
(0.405)\end{array}$ & $\begin{array}{l}-0.102 \\
(0.551)\end{array}$ & $\begin{array}{l}-0.342 \\
(0.582)\end{array}$ & $\begin{array}{c}0.521 \\
(0.500)\end{array}$ & $\begin{array}{l}0.0307 \\
(0.385)\end{array}$ \\
\hline No. of siblings & $\begin{array}{l}0.0011 \\
(0.035)\end{array}$ & $\begin{array}{c}-0.0293 \\
(0.038)\end{array}$ & $\begin{array}{c}-0.0611 \\
(0.038)\end{array}$ & $\begin{array}{c}-0.0207 \\
(0.039)\end{array}$ & $\begin{array}{c}-0.0274 \\
(0.025)\end{array}$ \\
\hline Family structure & $\begin{array}{c}0.168 \\
(0.152) \\
\end{array}$ & $\begin{array}{l}0.0237 \\
(0.156)\end{array}$ & $\begin{array}{l}0.0487 \\
(0.145)\end{array}$ & $\begin{array}{l}-0.259 \\
(0.190)\end{array}$ & $\begin{array}{c}-0.006 \\
(0.107)\end{array}$ \\
\hline Observations & 397 & 397 & 397 & 397 & 397 \\
\hline Wald $\chi^{2}$ & 11.73 & $19.25 *$ & $44.55^{* * *}$ & $26.07^{* * *}$ & $29.30 * * *$ \\
\hline Pseudo $R^{2}$ & 0.0036 & 0.0053 & 0.0102 & 0.0087 & 0.065 \\
\hline
\end{tabular}

*** $p<0.01,{ }^{* *} p<0.05,{ }^{*} p<0.10$. Numbers in parentheses are standard errors.

\section{Discussion}

Generativity is demonstrated to be a robust and consistent determinant of SH, while SVO is not. The previous literature demonstrates that prosocial actions (not preferences) lead to an increase in happiness $[44,47,66,67]$, while there is little research that examines people's happiness with different social value orientations or preferences. It is generally considered that proself and prosocial people may have their own way to be happy and tend to consistently make proself and prosocial choices, respectively, because the proselves (prosocials) become happier by being more proself (prosocial) than by being more prosocial (proself). However, we conjecture that the magnitude of a change in individual SH may neither be characterized by SVO nor be different between prosocial and proself people, based on the fact that the SVO variable is insignificant in our analyses. Rather, the magnitude of a change in individual SH may be more attributed to something more personal or person-specific factors such as self-esteem, self-positivity or self-efficacy, along with SVO.

Generativity is calculated by the scores of how many activities from the generativity behavioral checklist (GBC) people have taken in the last two months. The GBC contains certain activities that both prosocial and proself people are likely to perform in their daily lives. Some activities in the GBC such as "learned a new skill," "produced a plan for an organization or group outside my family" and "was elected or promoted to a leadership position" may be likely to be performed by proself people. 
On the other hand, the activities in the GBC such as "gave money to a charity," "taught somebody a skill" and "made something for somebody and then gave it to them" may be likely to be performed by prosocial people.

It appears that there are mainly two channels of motivations to be more generative for future generations: (i) proself and (ii) prosocial channels, implying that the basic motives behind generative actions could be different. Proself people may be driven by "legacy motives," whereas prosocial people may be driven by "motives of helping hands" for future generations $[8,68,69]$. Therefore, it is our conjecture that generative actions may be able to uniformly contribute to individual $\mathrm{SH}$, irrespective of prosocial and proself motives behind the actions, and, therefore, generativity is a consistent and robust determinant of $\mathrm{SH}$ in the analysis. If this is the case, future design approach and/or some other social devices suggested by the authors in [24-26,49,70-72] will play a significant role in connecting the current generation to future generations as a possible institutional framework to increase or maintain the generativity for intergenerational wellbeing and sustainability.

Our results also show that PRH and OSH vary by residence area and that urban people have higher PRH and OSH than rural people. Life in a rural society is known to be homogeneous in terms of choice sets, social status and sources of happiness (A PRH question in the GBC uses a 7-point Likert scale, and its anchors are "less happy" and "more happy." This means that the middle point of the scale (e.g., score of 4) describes the subject who is "as happy as his/her peers." An average PRH for rural subjects is closer to four points than that for urban subjects, implying that rural subjects might feel closer to being "as happy as their peers" than urban ones). For instance, a main and common entertainment among rural people in Bangladesh is attending a social gathering, "mela," in which all people in the village can come and gather at the same time and place. In that gathering, people enjoy all the social and communal activities together by sharing a feeling of "commonality." On the other hand, urban areas are heterogeneous in terms of choice sets, social status and sources of happiness, as there are more possibilities in many aspects. For instance, entertainment in urban areas includes wider varieties with more accessibility, giving people more freedom in their choices. In this type of urban environment, people can express different preferences and value judgments over what to do and how to spend, inducing themselves to see a "difference" in how each person is distinct from one another. Therefore, urban people may be able to consider themselves as happy in their own way because they are considered to have chosen to be so, leading urban people to feel happier compared to their peers than rural people.

Cities are predicted to expand and grow with further urbanization over the next 50 years, and $65-75 \%$ of the earth's population will reside in cities in Asia and Africa [73,74]. Economic theory establishes that urbanization brings about an increase in people's income, potentially implying that economic growth with urbanization has a positive effect on happiness along with our result as well as those of the previous literature [31,75-79]. However, behavioral sciences and social psychology report that urbanization is changing human societies in the way that people's generativity declines, the so-called "generativity crisis" [8,80]. Sasaki [80] claims that rapid economic growth, urbanization and social changes in Japan have led to a decline in people's generativity. Other scholars argue that the degrowth of economies is inevitable to ensure the wellbeing of future generations [81-85]. Given the two possible paths of growth and degrowth, a natural question arises: "which is better, economic growth with urbanization or degrowth for the current and future generations' wellbeing?" Our results in this research clearly suggest that the answer depends on whether and how economic growth with urbanization (and/or degrowth) affects generativity and in turn sustainability, which should be addressed and established in future research.

\section{Conclusions}

This paper has analyzed the relationships among subjective happiness $(\mathrm{SH})$, generativity and social preferences within a single analytical framework, posing a research question "Are people happier by being prosocial and/or generative for sustainability?" We conduct a survey experiment, collecting 
data from five subjective happiness scales, generativity, SVO and sociodemographic variables in an urban city (Dhaka) and rural areas (Bogra and Gaibandha) in Bangladesh. With the data, we empirically characterize determinants of $\mathrm{SH}$ with a specific focus on generativity and $\mathrm{SVO}$, controlling for other factors. The statistical analysis shows a positive association between $\mathrm{SH}$ and generativity, irrespective of the type of happiness scale, while SVO does not exhibit any significant effect. Rural people have lower peer relative happiness than urban people, and household income has a positive relationship with general subjective happiness, leading each of these factors to be significant in overall subjective happiness. In summary, generativity, income and residence area are main determinants of happiness, implying that further urbanization, which is expected to occur in the future, will positively affect people's happiness if it can bring about an increase in generativity. It has been claimed that democracy and capitalism are not institutions that can maintain sustainability when people pursue happiness, and there are no social institutions or regimes to be able to do so $[10,17]$. This is exemplified by the emergence of "climate change" and "accumulation of government debts" in many countries for the last decades. Our paper contributes to the existing knowledge by answering whether or not people become happier by being more generative. The answer is identified to be "yes," and thus the "future design," which seeks to connect the current generation with future generations, shall be considered and recommended as a promising institution to maintain sustainability through enhancing generativity along with happiness $[25,26,70]$.

We note some limitations of our study and future avenues of research. This paper studies happiness, generativity and SVO with a small sample size because of budget and time constraints in only one country (i.e., Bangladesh), which is considered a culturally and ethnically homogeneous society. We believe that further studies with the same analytical framework and with a large sample size in other countries will widen our understanding of generativity and some missing factors in relation to $\mathrm{SH}$. In addition, we do not study the detailed mechanism of how and why generativity and happiness are positively associated. Therefore, future studies should be able to focus on addressing how each of the generative behaviors more directly influences happiness than the others by collecting finer individual behavioral data. Most importantly, future research should also focus on clarifying whether and how economic growth affects generativity and happiness within a single framework. To this end, "future design," as a new field of research, can play an important role through applying some laboratory and field experiments and/or neuroscience to understand how people perceive or the brains react when people take and observe generative actions. These caveats notwithstanding, it is our belief that this research is an important first step in understanding people's happiness, generativity and social preferences in developing countries for the betterment and sustainability of societies.

Supplementary Materials: The following are available online at http:/ /www.mdpi.com/2071-1050/11/19/5256/s1. A sample of our questionnaire we referred to at the end of the first paragraph in page 5 is available on the web page of this publication or upon request.

Author Contributions: Conceptualization, M.E.S., S.S. and K.K.; Data curation, M.E.S. and S.S.; Formal analysis, M.E.S., S.S. and K.K.; Funding acquisition, K.K.; Investigation, M.E.S., S.S. and K.K.; Methodology, M.E.S. and K.K.; Project administration, M.E.S., S.S. and K.K.; Resources, M.E.S. and K.K.; Software, M.E.S. and K.K.; Supervision, K.K.; Validation, K.K.; Visualization, M.E.S. and K.K.; Writing-original draft, M.E.S. and K.K.; Writing一review and editing, M.E.S., S.S. and K.K.

Funding: We are grateful to the financial supports from the Japan Society for the Promotion of Science (JSPS) as the Grant-in-Aid for Scientific Research B (19H01485) and Kochi University of Technology.

Acknowledgments: The authors thank anonymous referees, Makoto Kakinaka, Hiroaki Miyamoto and Yoshinori Nakagawa for their helpful comments, advice and supports.

Conflicts of Interest: The authors declare no conflict of interest.

\section{References}

1. Lyubomirsky, S. Why are some people happier than others? The role of cognitive and motivational processes in well-being. Am. Psychol. 2001, 56, 239-249. [PubMed] 
2. Sato, W.; Kochiyama, T.; Uono, S.; Kubota, Y.; Sawada, R.; Yoshimura, S.; Toichi, M. The structural neural substrate of subjective happiness. Sci. Rep. 2015, 5, 16891. [PubMed]

3. Diener, E.; Horwitz, J.; Emmons, R.A. Happiness of the very wealthy. Soc. Indic. Res. 1985, 16, $263-274$.

4. Frey, B.S. Happiness: A Revolution in Economics; The MIT Press: Cambridge, MA, USA, 2008.

5. Knight, J.; Lina, S.O.; Gunatilaka, R. Subjective well-being and its determinants in rural China. China Econ. Rev. 2009, 20, 635-649.

6. Asadullah, M.N.; Chaudhury, N. Subjective well-being and relative poverty in rural Bangladesh. J. Econ. Psychol. 2012, 33, 940-950.

7. McAdams, D.P.; De St. Aubin, E. A theory of generativity and its assessment through self-report, behavioral acts, and narrative themes in autobiography. J. Pers. Soc. Psychol. 1992, 62, 1003-1015.

8. Timilsina, R.R.; Kotani, K.; Kamijo, Y. Generativity and social value orientation between rural and urban societies in a developing country. Futures 2019, 105, 124-132.

9. Friedman, M. Capitalism and Freedom; University of Chicago Press: Chicago, IL, USA, 2002.

10. Schumpeter, J.A. Capitalism, Socialism, and Democracy, 3rd ed.; Harper Perennial Modern Classics: New York, NY, USA, 2008.

11. Roskin, M.; Cord, R.; Medeiros, J.; Jones, W. Political Science: An Introduction; Pearson: London, UK, 2017.

12. Headey, B.; Muffels, R.; Wooden, M. Money does not buy happiness: Or does it? A reassessment based on the combined effects of wealth, income and consumption. Soc. Indic. Res. 2007, 87, 65-82.

13. Kolstad, C.D. Environmental Economics; Oxford University Press: Oxford, UK, 2010.

14. Gilovich, T.; Kumar, A.; Jampol, L. A wonderful life: Experiential consumption and the pursuit of happiness. J. Consum. Psychol. 2015, 25, 152-165.

15. Chen, Y. Problems of communism and changes in China. J. Contemp. China 1993, 2, 82-86.

16. Portney, P.R.; Stavins, R.N. (Eds.) Public Policies for Environmental Protection, 2nd ed.; Resources for the Future: Washington, DC, USA, 2000.

17. Hanley, N.; Shogren, J.F.; White, B. Environmental Economics, 2nd ed.; Macmillan Education UK: London, UK, 2006.

18. Benson, M.H.; Craig, R.K. The end of sustainability. Soc. Nat. Resour. 2014, 27, 777-782.

19. Goodland, R. The concept of environmental sustainability. Annu. Rev. Ecol. Syst. 1995, 26, 1-24.

20. Glotzbach, S.; Baumgartner, S. The relationship between intragenerational and intergenerational ecological justice. Environ. Values 2012, 21, 331-355.

21. Timilsina, R.R.; Kotani, K.; Kamijo, Y. Sustainability of common pool resources. PLoS ONE 2017, 12, e0170981.

22. Milfont, T.L.; Sibley, C.G. Exploring the concept of environmental generativity. Int. J. Hisp. Psychol. 2011, 4, 21-30.

23. Alisat, S.; Norris, J.E.; Pratt, M.W.; Matsuba, M.K.; McAdams, D.P. Caring for the Earth: Generativity as a mediator for the prediction of environmental narratives from identity among activists and nonactivists. Identity Int. J. Theory Res. 2014, 14, 177-194.

24. Nakagawa, Y.; Hara, K.; Saijo, T. Becoming Sympathetic to the Needs of the Future Generations: A Phenomenological Study of Participation in Future Design Workshop; Working paper SDES-2017-4; Research Institute for Future Design, Kochi University of Technology: Kochi, Japan, 2017.

25. Hara, K.; Yoshioka, R.; Kuroda, M.; Kurimoto, S.; Saijo, T. Reconciling intergenerational conflicts with imaginary future generations: Evidence from a participatory deliberation practice in a municipality in Japan. Sustain. Sci. 2019, forthcoming.

26. Saijo, T. Future Design; Working paper SDES-2019-5; Research Institute for Future Design, Kochi University of Technology: Kochi, Japan, 2019.

27. Easterlin, R.A. Explaining happiness. Proc. Natl. Acad. Sci. USA 2003, 100, 11176-11183. [PubMed]

28. Biswas-Diener, R.; Diener, E.; Tamir, M. The psychology of subjective well-being. Daedalus 2004, 133, 18-25.

29. Kahneman, D.; Krueger, A.B.; Schkade, D.; Schwarz, N.; Stone, A.A. Would you be happier if you were richer? A focusing illusion. Science 2006, 312, 1908-1910. [PubMed]

30. Asadullah, M.N.; Xiao, S.; Yeoh, E. Subjective well-being in China, 2005-2010: The role of relative income, gender, and location. China Econ. Rev. 2018, 48, 83-101.

31. Requena, F. Rural-urban living and level of economic development as factors in subjective well-being. Soc. Indic. Res. 2015, 128, 693-708. 
32. Kim, D. Cross-national pattern of happiness: Do higher education and less urbanization degrade happiness? Appl. Res. Qual. Life 2018, 13, 21-35.

33. De St. Aubin, E.; McAdams, D.P. The relations of generative concern and generative action to personality traits, satisfaction/happiness with life, and ego development. J. Adult Dev. 1995, 2, 99-112.

34. Keyes, C.L.M.; Ryff, C.D. Generativity in adult lives: Social structural contours and quality of life consequences. In Generativity and Adult Development: How and Why We Care for the Next, Generation; McAdams, D.P., de St. Aubin, E., Eds.; Amrican Psychological Association: Washington, DC, USA, 1998; Chapter 7, pp. 227-263.

35. Stewart, A.J.; Ostrove, J.M.; Helson, R. Middle aging in women: Patterns of personality change from the 30s to the 50s. J. Adult Dev. 2001, 8, 23-37.

36. Hofer, J.; Busch, H.; Chasiotis, A.; Kärtner, J.; Campos, D. Concern for generativity and its relation to implicit pro-social power motivation, generative goals, and satisfaction with life: A cross-cultural investigation. J. Pers. 2007, 76, 1-30.

37. Huta, V.; Zuroff, D.C. Examining mediators of the link between generativity and well-being. J. Adult Dev. 2008, 14, 23-47.

38. Hofer, J.; Busch, H.; Au, A.; Šolcová, I.P.; Tavel, P.; Wong, T.T. For the benefit of others: Generativity and meaning in life in the elderly in four cultures. Psychol. Aging 2014, 29, 764-775.

39. Hofer, J.; Busch, H.; Au, A.; Šolcová, I.P.; Tavel, P.; Wong, T.T. Generativity does not necessarily satisfy all your needs: Associations among cultural demand for generativity, generative concern, generative action, and need satisfaction in the elderly in four cultures. Dev. Psychol. 2016, 52, 509-519.

40. Au, A.; Lai, S.; Wu, W.; Hofer, J.; Busch, H.; Šolcová, I.P.; Tavel, P.; Cheng, S.T. Generativity and positive emotion in older adults: Mediation of achievement and altruism goal attainment across three cultures. J. Happiness Stud. 2019, forthcoming.

41. Jia, F.; Alisat, S.; Soucie, K.; Pratt, M. Generative concern and environmentalism. Emerg. Adulthood 2015, $3,306-319$.

42. Jia, F.; Soucie, K.; Alisat, S.; Pratt, M. Sowing seeds for future generations. Int. J. Behav. Dev. 2016, 40, 466-470.

43. Matsuba, M.K.; Pratt, M.W.; Norris, J.E.; Mohle, E.; Alisat, S.; McAdams, D.P. Environmentalism as a context for expressing identity and generativity: Patterns among activists and uninvolved youth and midlife adults. J. Pers. 2012, 80, 1091-1115. [PubMed]

44. Dunn, E.W.; Aknin, L.B.; Norton, M.I. Spending money on others promotes happiness. Science 2008, 319, 1687-1688. [PubMed]

45. Konow, J.; Earley, J. The hedonistic paradox: Is homo economicus happier? J. Public Econ. 2008, 92, 1-33.

46. Aknin, L.B.; Dunn, E.W.; Norton, M.I. Happiness runs in a circular motion: Evidence for a positive feedback loop between prosocial spending and happiness. J. Happiness Stud. 2012, 13, 347-355.

47. Dunn, E.W.; Aknin, L.B.; Norton, M.I. Prosocial spending and happiness. Curr. Dir. Psychol. Sci. 2014, 23, 41-47.

48. Nelson, S.K.; Layous, K.; Cole, S.W.; Lyubomirsky, S. Do unto others or treat yourself? The effects of prosocial and self-focused behavior on psychological flourishing. Emotion 2016, 16, 850-861.

49. Kamijo, Y.; Komiya, A.; Mifune, N.; Saijo, T. Negotiating with the future: Incorporating imaginary future generations into negotiations. Sustain. Sci. 2017, 12, 409-420.

50. Shahrier, S.; Kotani, K.; Saijo, T. Intergenerational sustainability dilemma and the degree of capitalism in societies: A field experiment. Sustain. Sci. 2017, 12, 957-967.

51. Varian, H.R. Microeconomic Analysis, 3rd ed.; Norton \& Company: New York, NY, USA, 1992.

52. Carlsson, F.; Johansson-Stenman, O.; Nam, P.K. Social preferences are stable over long periods of time. J. Public Econ. 2014, 117, 104-114.

53. Van Lange, P.A.; Agnew, C.R.; Harinck, F.; Steemers, G.E.M. From game theory to real life: How social value orientation affects willingness to sacrifice in ongoing close relationships. J. Pers. Soc. Psychol. 1997, 73, 1330-1344.

54. McAdams, D.P.; Hart, H.M.; Maruna, S. The anatomy of generativity. In Generativity and Adult Development: How and Why We Care for The next Generation; McAdams, D.P., de St. Aubin, E., Eds.; American Psychological Association: Washington, DC, USA, 1998; Chapter 1, pp. 7-43.

55. Lyubomirsky, S.; Lepper, H.S. A measure of subjective happiness: Preliminary reliability and construct validation. Soc. Indic. Res. 1999, 46, 137-155. 
56. Van Lange, P.A.; Bekkers, R.; Schuyt, T.N.M.; Vugt, M.V. From games to giving: Social value orientation predicts donations to noble causes. Basic Appl. Soc. Psych. 2007, 29, 375-384.

57. Tuchtenhagen, S.; Bresolin, C.; Tomazoni, F.; da Rosa, G.; Del Fabro, J.; Mendes, F.; Antunes, J.; Ardenghi, T. The influence of normative and subjective oral health status on schoolchildren's happiness. BMC Oral Health 2015, 15, 1-8.

58. Sato, W.; Kochiyama, T.; Uono, S.; Sawada, R.; Kubota, Y.; Yoshimura, S.; Toichi, M. Resting-state neural activity and connectivity associated with subjective happiness. Sci. Rep. 2019, 9, 12098.

59. Shahrier, S.; Kotani, K.; Kakinaka, M. Social value orientation and capitalism in societies. PLoS ONE 2016, 11, e0165067.

60. Dewan, A.; Corner, R. Dhaka Megascity: Geospatial Perspectives on Urbanisation, Environment and Health; Springer: Dordrecht, The Netherlands, 2014.

61. Bangladesh Bureau of Statistics. Population and Housing Census; Technical report; Bangladesh Bureau of Statistics: Dhaka, Bangladesh, 2011.

62. Bangladesh Bureau of Statistics. Labour Market Information System (LMIS); Technical report; Bangladesh Bureau of Statistics: Dhaka, Bangladesh, 2015.

63. Wooldridge, J.M. Introductory Econometrics, 5th ed.; South-Western Cengage Learning: Mason, OH, USA, 2013 .

64. Wooldridge, J.M. Econometric Analysis of Cross Section and Panel Data, 2nd ed.; MIT Press: Cambridge, MA, USA, 2010.

65. Ball, R.; Chernova, K. Absolute income, relative income, and happiness. Soc. Indic. Res. 2007, 88, 497-529.

66. Konow, J. Mixed feelings: Theories of and evidence on giving. J. Public Econ. 2010, 94, $279-297$.

67. Koch, $\mathrm{C}$. The virtue ethics hypothesis: Is there a nexus between pro-social behavior and well-being? SSRN Electron. J. 2015. [CrossRef]

68. Bang, H.M.; Koval, C.Z.; Wade-Benzoni, K.A. It's the thought that counts over time: The interplay of intent, outcome, stewardship, and legacy motivations in intergenerational reciprocity. J. Exp. Soc. Psychol. 2017, 73, 197-210.

69. Wade-Benzoni, K.A. Legacy motivations \& the psychology of intergenerational decisions. Curr. Opin. Psychol. 2019, 26, 19-22. [PubMed]

70. Saijo, T. Future Design: Concept for a Ministry of the Future; Working paper SDES-2015-14; Research Institute for Future Design, Kochi University of Technology: Kochi, Japan, 2015.

71. Shahrier, S.; Kotani, K.; Saijo, T. Intergenerational Sustainability Dilemma and a Potential Solution: Future Ahead and Back Mechanism; Working paper SDES-2017-9; Research Institute for Future Design, Kochi University of Technology: Kochi, Japan, 2017

72. Timilsina, R.R.; Kotani, K.; Saijo, T. Accountability as a Resolution for Intergenerational Sustainability Dilemma; Working paper SDES-2019-2; Research Institute for Future Design, Kochi University of Technology: Kochi, Japan, 2019.

73. American Association for the Advancement of Science. Rise of the city. Science 2016, 352, 906-907.

74. Wigginton, N.S.; Fahrenkamp-Uppenbrink, J.; Wible, B.; Malakoff, D. Cities are the future. Science 2016, 352, 904-905. [PubMed]

75. Wheaton, W.C.; Lewis, M.J. Urban wages and labor market agglomeration. J. Urban Econ. 2002, 51, 542-562.

76. Bloom, D.E.; Canning, D.; Fink, G. Urbanization and the wealth of nations. Science 2008, 319, 772-775.

77. Zhang, X.Q. The Economic Role of Cities; United Nations Human Settlements Programme: Nairobi, Kenya, 2011.

78. Han, M.J.N.; Kim, M.J. Green environments and happiness level in housing areas toward a sustainable life. Sustainability 2019, 11, 4768.

79. Lin, C.; Zhao, G.; Yu, C.; Wu, Y. Smart city development and residents' well-being. Sustainability 2019, 11, 676.

80. Sasaki, T. Generativity and the politics of intergenerational fairness. In The Generative Society: Caring for Future Generations; de St. Aubin, E., McAdams, D.P., Kim, T.C., Eds.; Academic Press: Cambridge, MA, USA, 2004; Chapter 13, pp. 211-219.

81. Weitzman, M.L. Sustainability and technical progress. Scand. J. Econ. 1997, 99, 1-13.

82. Schneider, F.; Kallis, G.; Martinez-Alier, J. Crisis or opportunity? Economic degrowth for social equity and ecological sustainability. Introduction to this special issue. J. Clean. Prod. 2010, 18, 511-518. 
83. Alexander, S. Planned economic contraction: The emerging case for degrowth. Environ. Politics 2012, 21, 349-368.

84. Andreoni, V.; Galmarini, S. How to increase well-being in a context of degrowth. Futures 2014, 55, 78-89.

85. Buchs, M.; Koch, M. Challenges for the degrowth transition: The debate about wellbeing. Futures 2019, 105, 155-165. 